F O U N D A T O N S F C O M P U T N G A N D D E C I S I O N C I E N C E S Vol. 43

(2018)

No. 1

ISSN 0867-6356

DE GRUYTER

DOI: $10.1515 /$ fcds-2018-0001

e-ISSN 2300-3405

\title{
Obituary of Bernard Roy (1934-2017)
}

\author{
Roman Słowiński *
}

Professor Bernard Roy passed away on October 28, 2017. He was a pioneer of Operational Research (OR) in Europe and a world-wide recognized expert in the area of Multiple Criteria Decision Aiding (MCDA). He was a founder of the EURO Working Group on MCDA, and, more generally, a founder of the European School of MCDA. He was also a president of EURO and member of the editorial board of the Foundations of Computing and Decision Sciences since 1979.

Bernard Roy has made a very significant and innovative contribution to OR. His major breakthrough works were first in graph theory and project scheduling, and then in multiple criteria decision aiding. Among his many achievements, he is the father of the "activity on node" project scheduling technique and of the famous ELECTRE methods. Through his research, teaching, consulting, and service to the community, he was one of the major promoters of OR techniques in Europe.

Bernard Roy was born on March 15, 1934 in Moulins-sur-Allier, a medium-sized town in the center of France. He got a degree in Mathematics at the Université de Paris. After he obtained his Licence (Rational Mechanics) in September 1954, he joined IEP (Institut d'Études Politiques), a relatively special Grande École mainly oriented towards Economics and Political Science, and the Institut de Statistique de l'Université de Paris (ISUP), an interfaculty department granting diplomas in Statistics and Probability. At those times Bernard discovered Operations Research and decided to apply Mathematics in the real world. In July 1956, Bernard got a position of researcher at the Centre National de la Recherche Scientifique (CNRS). He was also recruited as intern at Électricité de France (EDF, the newly nationalized electricity company) where he started to apply linear programming. In that period, Bernard completed his Master's thesis at ISUP, and he wrote his first research paper. Bernard married Françoise in July 1957 (see the picture below). They will have six children: Sylvie (1958†), Laurence (1961), Isabelle (1964), Solange (1966), Patrice (1968) and Philippe (1970†). After leaving CNRS, Bernard was recruited by a newly created consulting company SEPRO specialized in OR, but very soon, in

*Institute of Computing Science, Poznań University of Technology, Piotrowo 2, 60-965 Poznań and Polish Academy of Sciences, Roman.Slowinski@cs.put.poznan.pl 
October 1957, he joined the Société de Mathématiques Appliquées (SMA), a joint venture between Paribas and an independent consulting company. SMA quickly became SEMA (Société d'Économie et de Mathématiques Appliquées) and, after having created several subsidiaries in Europe, SEMA (Metra International). After translating into French the new book of C.W. Churchman, R.L. Ackoff and E.L. Arnoff "Introduction to Operations Research", in 1958, Bernard started to work on applied OR problems. Bernard worked on a variety of problems such as: scheduling, probability and queuing theory, data analysis, transportation studies, cutting stock, location, finance. While working on several scheduling problems, he developed and refined the "activity on node formulation" in project scheduling. In between contracts, Bernard started working on his PhD dissertation devoted to Graph Theory and its applications. He received his $\mathrm{PhD}$ in 1961 from the Université de Paris, under the supervision of Claude Berge. In 1962, Bernard joined a scientific team called "Direction Scientifique", created by Jacques Lesourne within SEMA with the aim of helping consultants applying new OR techniques. He took the direction of that team in 1964. At the same time, Bernard was appointed as editor-in-chief (position that he maintained until 1977) of a quarterly journal called METRA launched by SEMA to popularize the new management techniques it promoted. The work of Bernard on multiple criteria decision started in the mid-sixties on the basis of real-world problems submitted by SEMA consultants. This led him to the development of the first ELECTRE method (ELECTRE I). In 1969 and 1970, Bernard published the two volumes of his book on Graph Theory. During these consulting years, Bernard taught OR courses at the Centre Inter-armées de Recherche Opérationnelle (a permanent education course program in OR for French officers) and headed together with Claude Berge a seminar on Graph Theory and Combinatorial problems. After giving a doctoral course on OR at the newly created Universite Paris Dauphine, in 1971 he was appointed there Associate Professor in Mathematics, and, one year after, Full Professor. He kept his position at SEMA till 1974, and further he stayed in contact with SEMA till 1979. In 1974 Bernard created a research group called LAMSADE (Laboratoire d'Analyse et Modélisation de Systèmes pour l'Aide à la DEcision), focused on "analysis and modelling of systems for decision aiding", that became affiliated to the CNRS in 1976. This was one of the few research groups in France oriented towards OR. In 1980, he became Scientific Advisor at RATP. His research at LAMSADE was more and more oriented towards Multiple Criteria Decision Aiding (MCDA). Building on this research, he developed an original methodology for decision aiding. More recently, he has been working on robustness analysis. He also took several important responsibilities within Universite Paris Dauphine, including the direction of a doctoral school. Bernard retired in 2001, but he continued to give some lectures and held a seminar at LAMSADE as Emeritus Professor until the end of his life.

During the first EURO conference which was held in Brussels in 1975, Bernard Roy founded the EURO Working Group on "Multiple Criteria Decision Aiding", which regularly held two annual meetings since then (in Spring and Autumn). It hold its meeting three times in Poznań. The group aims at promoting original research on MCDA at the European level. The meetings of the group are not conferences. They are designed so as to foster discussions and exchanges. The group has around 350 
members, from about 30 countries, and meetings usually gather between 50 and 100 persons. The success of the group is attested by the fact that most texts on MCDA now speak of a "European school of MCDA" Bernard was president of this EURO Working Group during 25 years, and in 2010 he became its Honorary Chairman.

Bernard Roy was President Elect and President of EURO in years 1983-1986. He was also the Honorary President of ROADEF (the French association of operational research and decision aiding). Seven great universities distinguished Bernard Roy with the Doctor Honoris Causa degree (Vrije Universiteit Brussels, Belgium, 1978, Université de Liège, Belgium, 1978, Université de Fribourg, Switzerland, 1982, Poznań University of Technology, Poland, 1992, Université Laval, Canada, 1998, Technical University of Crete, Greece, 2002, University of Catania, 2009). He received the "Prix Hermès d'excellence en recherché" from the Faculty of Business Administration, Laval University (Québec, Canada) in 1991, the EURO Gold Medal in 1992, and the MCDM Gold Medal granted by the International MCDM Society in 1995. In 2015, he was also decorated by the EURO Distinguished Service Medal Award. In September 2017, during the 86th meeting of the EURO Working Group on MCDA in Paris, Bernard Roy received the Medal of the Polish Academy of Sciences corresponding to the highest scientific distinction conferred on personalities exterior to the Academy "for merits particularly related to the social role of science".

Bernard Roy was the author of several books and hundreds of research papers. He has been the advisor of numerous graduate and doctoral students.

Bernard Roy's main contributions focus on two broad themes:

- Graph Theory with path-breaking contributions to the theory of flows in networks and project scheduling (with the invention of the 'activity-on-nodes' method).

- Multiple Criteria Decision Aiding with the invention of the family of ELECTRE methods and methodological contributions to decision aiding that have led to the creation of the European School of MCDA.

He was active in research until the last days of his life. His recent research addressed robustness in operational research and decision aiding, and multiple criteria tools for collective decision (called "concertation" in French).

His personality was non-dissociable from his family, and especially his lovely wife Françoise, with whom he had five children. Françoise passed away in 2015. Their house in Sèvres was particularly warm and friendly to the guests. Meetings at their table covered with dishes prepared by Françoise and wines chosen by Bernard were a feast at once gastronomic and intellectual, refined in simplicity. 


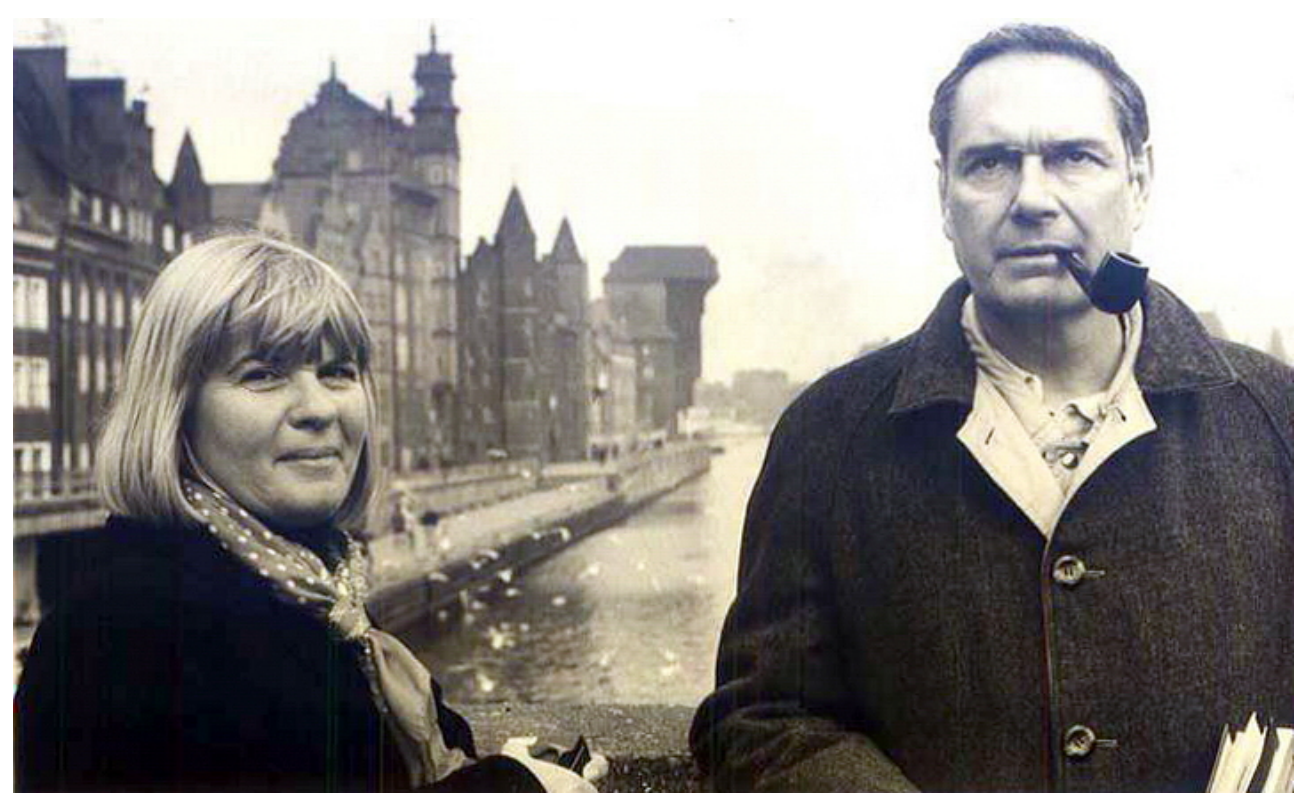

Bernard Roy and his wife Françoise in Gdańsk in 1988 (C R. Słowiński)

In his office at LAMSADE, Bernard Roy had two portraits: those of Descartes and Pascal. I would say that they represented a mix of rationality and spirituality peculiar to him.

Despite his overwhelming scientific esteem, Professor Bernard Roy was a modest and considerate person. He radiated enthusiasm and kind encouragement for the young. We will keep a grateful memory of him alive. 